\title{
Psychiatric comorbidity in patients with chronic daily headache and migraine: a selective overview including personality traits and suicide risk
}

\author{
Maurizio Pompili · Daniela Di Cosimo • \\ Marco Innamorati - David Lester • \\ Roberto Tatarelli $\cdot$ Paolo Martelletti
}

Received: 17 April 2009/Accepted: 19 May 2009/Published online: 25 June 2009

(C) Springer-Verlag 2009

\begin{abstract}
Studies on the prevalence and impact of psychiatric disorders among headache patients have yielded findings that have clarified the relationship between migraine and major affective disorders, anxiety, illicit drug abuse, nicotine dependence, and suicide attempts. Studies in both clinical and community-based settings have demonstrated an association between migraine and a number of specific psychiatric disorders. In large-scale populationbased studies, persons with migraine are from 2.2 to 4.0 times more likely to have depression. In longitudinal studies, the evidence supports a bidirectional relationship between migraine and depression, with each disorder increasing the risk of the other disorder. Although a strong association has been demonstrated consistently for migraine and major depression, especially for migraine with aura,
\end{abstract}

M. Pompili $(\bowtie) \cdot$ D. Di Cosimo · R. Tatarelli

Department of Psychiatry, Sant'Andrea Hospital,

"Sapienza" University of Rome,

1035 Via di Grottarossa, 00189 Rome, Italy

e-mail: maurizio.pompili@uniroma1.it;

mpompili@mclean.harvard.edu

M. Pompili

McLean Hospital Harvard Medical School,

Belmont, MA, USA

M. Innamorati

Universitá Europea di Roma, Rome, Italy

D. Lester

The Richard Stockton College of New Jersey,

Pomona, NJ, USA

P. Martelletti

Department of Medical and Molecular Sciences,

2nd School of Medicine, Sant'Andrea Hospital,

"Sapienza" University of Rome, Rome, Italy there has been less systematic research on the links between migraine and bipolar disorder. This review will focus on the way in which psychiatric disorders decrease the quality of life and result in a worse prognosis, chronicity of the disease, and a worse response to treatment. Short-term pharmaceutical care intervention improves the patients' mental health, but it does not significantly change the number and severity of headaches. The increase in self-efficacy and mental health associated with pharmaceutical care may be instrumental in improving the long-term pharmacotherapy of patients with migraine and headache.

Keywords Psychiatric disorders · Headache . Suicide risk - Treatment

\section{Introduction}

Chronic daily headache $(\mathrm{CDH})$ refers to a group of disorders in which headache occurs 15 or more days per month for at least 3 months [1-5] and includes: chronic migraine (CM), migraine with or without aura and migraine aura without headache, chronic tension-type headache (CTTH), hemicrania continua $(\mathrm{HC})$, and new daily persistent headache [6-8].

Chronic migraine (CM) affects $2.4 \%$ of the general population [5] and it is often comorbid with other conditions, such as depression (80\%) [9], anxiety $(70 \%)$ [9, 10], insomnia (71\%) [11], chronic fatigue (66\%) [12], and fibromyalgia (35\%) [13]. Recently, studies have viewed the relationship between migraine and psychiatric disorder as (1) bi-directional [14] since migraine patients have a more than threefold risk of developing depression and (2) specific [15] since the presence of migraine increases a patient's risk of developing depression or panic attack 
disorder and the presence of depression or panic attack disorder is associated with a greater risk of developing migraine.

Sheftel and Atlas [16], looking at clinical manifestations associated with daily chronic headache, found a high incidence of anhedonia, decreased concentration, decreased libido, decreased energy, and sleep disorders, all characteristic elements of depression. They proposed that headache is not simply a symptom of depression, but that headache and several mood and anxiety disorders are clinical entities that share some pathophysiological bases [15, 17-24], most likely disturbances in the serotonergic systems [20, 25-27].

\section{Epidemiology}

Epidemiological research has indicated an association between migraine and mood disorder with a lifetime prevalence of major depression three times higher among patients with migraine when compared with patients without migraine [28]. This comorbidity between $\mathrm{CDH}$ and psychiatric disorders seems to be more frequent in women, in chronic forms of migraine [29] and in first-degree relatives of patients with mood disorder and migraine [21]. Migraine with aura is strongly associated with an early age of onset of the mood disorder (OR 11.4, age $<15$ years; OR 5.6, age 15-24 years) [20]. Migraine, weekly or daily, occurs in $3-15 \%$ of children $[30,31]$ while $9-33 \%$ of individuals suffer from non-migraine headache at least monthly [31]. The prevalence of migraine is highest among patients with bipolar II disorder (77\%), and this is significantly different from the prevalence among bipolar I patients (14\%) [32]. The unipolar group has a prevalence of $46 \%$, in between the two bipolar groups [32]. This is in broad agreement with the study by Endicott [33], who found a 51\% prevalence of migraine in patients with characteristics similar to bipolar II patients. The results of some epidemiological studies are shown in Table 1.

\section{Psychiatric disorders and headache}

The presence of migraine or severe non-migraine headache increases a patient's risk of developing depression or panic attack disorder, whereas the presence of depression or panic attack disorder is associated with a greater risk of developing migraine, but not severe non-migraine headache [15]. Merikangas and colleagues [17], in a prospective study, supported the idea that anxiety induces or facilitates the onset of a primary headache, acting as trigger for the subsequent development of a mood disorder such as depression. People suffering from migraine were 12 times more likely to suffer from panic attacks [21] and 2.5 times more likely to suffer from depression.

Psychiatric comorbidity is more frequent in chronic pain syndromes, such as the chronic form of migraine [34]. It is important to distinguish between migraine with or without aura and aura without headache. In one population-based epidemiological study [17, 35], migraine with aura was associated with anxiety disorders, recurrent brief depression and hypomania, whereas only the phobic and panic disorders were more frequent among patients suffering from migraine without aura. Patients with tension-type headache did not differ from controls with respect to any of the affective or anxiety disorders. Oedegaard and colleagues [20] showed that a large number of patients presenting with major affective disorders have migraine aura without headache. These patients had a lower frequency of an affective temperament and a lower probability of having made a suicide attempt, as well as a higher age of onset of migraine auras relative to patients suffering from migraine with aura.

The more common psychiatric conditions related to migraine are depression, bipolar disorders, anxiety [(especially,
Table 1 Prevalence of migraine in bipolar disorder from previous studies
DIGS Diagnostic Interview for Genetic Studies, IHS International Headache Society

\begin{tabular}{llll}
\hline Source & Method & Sample size & $\begin{array}{l}\text { Migraine } \\
\text { prevalence (\%) }\end{array}$ \\
\hline Blehar et al. (1998) & Medical section of DIGS & $N=327$ & Total 21.1 \\
& & $F=186$ & Females 26.5 \\
Cassidy and Flanagan (1957) & Self-report of headache & $N=100$ & Total 49.0 \\
Mahmood et al. (1999) & Self-report of IHS migraine criteria & $N=81$ & Total 25.9 \\
& & $F=37$ & Females 27.0 \\
Marchesi et al. (1989) & Diagnosis by neurologist & $N=30$ & Total 20.0 \\
Fasmer (2001) & Administered IHS migraine criteria & $N=27$ & Bipolar I 13.0 \\
& & & Bipolar II 77.0 \\
Younes et al. (1986) & Mother's report of past diagnosis & $N=21$ & Total 28.6 \\
& of migraine & & Females $=0$ \\
& & & Male $=21$ \\
\hline
\end{tabular}


generalized anxiety disorders (GAD)] [17, 36] and somatoform disorders. These comorbid disorders have been identified in several epidemiological studies [22, 37-40] as well as in clinical studies of treatment-seeking patients [34, 40, 41]. The association between migraine and depression has also been studied in a number of large-scale community studies (Table 2).

The association of $\mathrm{CDH}$ with psychiatric disorders is controversial, especially with regard to depression (Table 3). Verri and colleagues [10] found an association between CDH and at least one psychiatric disorder in $90 \%$ of their patients, mainly GAD, followed by major depression (25\%) and dysthymia (17\%). Verri [10] and later Juang [48] confirmed that a longer major depressive disorder (or chronic depression) was the most frequent comorbidity among these patients, especially when the chronic headache had lasted for more than 5 years. However, Juang and colleagues [48] found that the frequency of any type of anxiety disorder was significantly higher in patients with chronic migraine than in those with CTTH. In prior research, the comorbidity between tension- type headache and psychiatric disorders has been investigated only in clinical populations, in which it has been showed that this association is more common in the chronic form of tension-type headache [14]. In fact, the frequency of anxiety and mood disorders were $3-15$ times higher in CTTH patients than in controls [14], and the frequencies reported were $21 \%$ for depression and $17 \%$ for anxiety disorders in these patients [41], with significantly higher anxiety and depression scores [41, 49]. Moreover, in previous studies, especially in the chronic form of tension-type headache, affective disorders were found to be frequent [50, 51]. Of the three studies conducted in clinical samples, none reported any significant differences in psychiatric comorbidity between migraine and tension-type headache $[49,52,53]$.

There has been less research on the role of personality disorders in headache. Mathew [54] found significantly higher abnormal personality profiles in $\mathrm{CDH}$ patients than in controls using the Minnesota Multiphasic Personality Inventory (MMPI) but found no difference in the profiles of patients with different subtypes of $\mathrm{CDH}$. In a small sample
Table 2 Select studies of the association between migraine and depression

\begin{tabular}{|c|c|c|c|}
\hline Study & Method & $\begin{array}{l}\text { Migraine and } \\
\text { depression } \\
\text { OR }(95 \% \text { CI })\end{array}$ & $\begin{array}{l}\text { Bi-directional } \\
\text { relationship } \\
\text { OR }(95 \% \mathrm{CI})\end{array}$ \\
\hline \multicolumn{4}{|l|}{ Longitudinal studies } \\
\hline Breslau et al. [37] & IHS migraine criteria & Not assessed & $\begin{array}{l}\text { New-onset migraine } \\
3.5(2.2-5.6) \\
\text { New-onset depression } \\
3.6(2.6-5.2)\end{array}$ \\
\hline Breslau et al. [15] & IHS migraine criteria & $3.5(2.6-4.6)$ & $\begin{array}{l}\text { New-onset migraine } \\
2.8(2.2-3.5) \\
\text { New-onset depression } \\
2.4(1.8-3.0)\end{array}$ \\
\hline Breslau et al. [42] & IHS migraine criteria & Not assessed & $\begin{array}{l}\text { New-onset migraine } \\
3.4(1.4-8.7) \\
\text { New-onset depression } \\
5.8(2.7-12.3)\end{array}$ \\
\hline \multicolumn{4}{|c|}{ Cross-sectional studies } \\
\hline Merikangas [43] & Diagnosis by neurologist & $2.2(1.1-4.8)$ & Not assessed \\
\hline Breslau et al. [15] & IHS migraine criteria & $3.5(2.6-4.6)$ & $\begin{array}{l}\text { New-onset migraine } \\
2.8(2.2-3.5) \\
\text { New-onset depression } \\
2.4(1.8-3.0)\end{array}$ \\
\hline Swartz [44] & IHS migraine criteria & $3.1(2.0-4.4)$ & $\begin{array}{l}\text { New-onset migraine } \\
0.68(0.02-2.0)\end{array}$ \\
\hline Zwart [45] & IHS migraine criteria & $2.7(2.3-3.2)$ & Not assessed \\
\hline McWilliams [46] & Diagnosis by neurologist & $2.8(2.2-3.7)$ & Not assessed \\
\hline Patel [47] & IHS migraine criteria & $\begin{array}{l}\text { Strict migraine } \\
2.7(2.2-3.3) \\
\text { Probable migraine } \\
1.9(1.5-2.4)\end{array}$ & Not assessed \\
\hline
\end{tabular}

IHS International Headache Society 
Table 3 Studies of psychiatric comorbidity in patients with chronic daily headache

\begin{tabular}{|c|c|c|c|c|}
\hline Study & $\begin{array}{l}\text { Criteria for headache } \\
\text { diagnosis }\end{array}$ & $\begin{array}{l}\text { Criteria for psychiatric } \\
\text { diagnosis }\end{array}$ & Mood disorders (\%) & $\begin{array}{l}\text { Anxiety } \\
\text { disorders }(\%)\end{array}$ \\
\hline Mathew et al. [54] & By their own criteria & MMPI subscore & 61 & Not assessed \\
\hline Verri et al. [10] & IHS & DSM IIIR (SCID-P) & $\begin{array}{l}\text { Major depressive } \\
\text { disorder: } 25 \\
\text { dysthymia: } 17\end{array}$ & GAD: 69.3 \\
\hline Puca et al. [34] & IHS & CIDI-by physicians & 45 & 56 \\
\hline $\begin{array}{r}\text { Mitsikostas and } \\
\text { Thomas [49] }\end{array}$ & $\begin{array}{l}\text { IHS + mixed type } \\
\text { headache }\end{array}$ & $\begin{array}{l}\text { Psychiatric evaluation } \\
\text { if HDRS }>16\end{array}$ & $\begin{array}{l}10(10 \text { in CTTH, } 19 \text { in } \\
\mathrm{MOH}, 9 \text { in mixed type })\end{array}$ & Not assessed \\
\hline Wang et al. [76] & $\begin{array}{l}\text { Adopted criteria of } \\
\text { Silberstein et al. } \\
\text { [2] + IHS for CTTH }\end{array}$ & DSM IV (GDS-S) & 29 & Not assessed \\
\hline Juang et al. [48] & $\begin{array}{l}\text { Adopted criteria of } \\
\text { Silberstein et al. [2] }\end{array}$ & DSM IV (MINI) & $\begin{array}{l}\text { Major depressive } \\
\text { disorder: } 55 \\
\text { dysthymia: } 11\end{array}$ & $\begin{array}{l}\text { GAD: } 5 \\
\text { Panic: } 27\end{array}$ \\
\hline Holroyd et al. [41] & IHS & BDI & $\begin{array}{l}\text { Major depressive } \\
\text { disorder: } 21\end{array}$ & 17 \\
\hline Atasoy et al. [75] & ICHD II & $\begin{array}{l}\text { DSM IV (SCID-II, } \\
\text { SCID-CV) }\end{array}$ & $\begin{array}{l}37.3 \text { (25 in Group C; } 51.6 \\
\text { in Group E; } 36.2 \text { in } \\
\text { Group M) }\end{array}$ & $\begin{array}{l}15.3 \text { (10.7 in Group C; } \\
16.1 \text { in Group E; } 17.2 \\
\text { in Group M) }\end{array}$ \\
\hline
\end{tabular}

MINI International Neuropsychiatric Interview; SCID the Structured Clinical Interview for DSM-IV; GDS-S Geriatric Depression Scale-short Form; IHS International Headache Society; CTTH Chronic Tension-type Headache; MMPI Minnesota Multiphasic Personality Inventory; HDRS Hamilton Depression Rating Scale; GAD Generalized Anxiety Disorder; BDI Beck Depression Inventory; CIDI Composite International Diagnostic Interview; ICHD-II The international classification of headache disorders, 2nd edition; $M O H$ Medication-Overuse Headache

study, high MMPI scores have been reported for the hypochondriasis and hysteria scales in $\mathrm{CDH}$ patients [55].

Galli and colleagues noted that only $9.6 \%$ of patients did not have familial occurrence of headache, with a half of the sample (49\%) showing both parents and grandparents complaining of headache. Galli et al. [56] stressed the importance of familial recurrence (mainly for the mother) for migraine and psychiatric disorders, but less so for tension-type headaches and psychiatric disorders. The tension-type headache group had higher temperament traits of emotionality and shyness, and lower sociability, than the migraine group [57]. A higher emotionality score was also found among the parents and siblings of tension-type headache children [57]. Thus, high scores for emotionality and shyness can be considered to be symptoms of 'behavioral inhibition' [58, 59], characterized by the traits of irritability, shyness, fearfulness, and introversion. In school-age children, the presence of this temperament seems to increase the vulnerability to depressive and multiple anxiety disorders [60, 61]. Tension-type headache patients may have, as a group, more behavioral, emotional, and temperament difficulties than children referred for migraine [56]. This finding seems to be in contrast with an epidemiological study in Finland, which found that psychiatric symptoms tended to be more strongly associated with migraine than with tension-type headache [62]. However, personality disorders are considered to be a complication for headache management [63-65], and significant headaches are a complaint of about $60 \%$ of patients with personality disorders presenting for acute treatment at a hospital emergency department [65].

\section{Suicide risk}

Suicide attempts seem to be more frequent in patients suffering from migraine than in the general population, especially in females and in patients with migraine with aura. This association has also been found in the general population [22, 35, 43, 66]. In contrast, the subtypes of $\mathrm{CDH}$, headache frequencies, or medication overuse were not correlated with the risk of attempted suicide [66].

Migraine with aura also independently predicted a high suicidal risk (score $>10$ on the MINI Suicidality Module) in adolescents with $\mathrm{CDH}$ [66], despite the fact that it is very difficult to predict suicide in youths. A history of migraine with aura, but not migraine without aura, has been found to be associated with an increased frequency of suicidal ideation and suicide attempts in patients with major depression in several studies [22, 39, 66], both current and previous affective episodes [20, 28]. Oedegaard and colleagues found that only $17 \%$ of patients having migraine aura without headache had made a suicide attempt, and these patients has the lowest frequency of affective temperaments as well as a higher age of onset of migraine auras [28]. However, the frequencies of suicidal ideation were approximately equal in the two groups of migraine patients [28]. 
Breslau [39] found an association of migraine with aura with suicide attempts that was not necessarily due to coexisting major depression. Migraine with aura alone was associated with significantly higher rates of suicidal tendencies. The risk of suicidal inclinations associated with migraine with aura and major depressive disorder was much higher than that for those with only major depressive disorder [67]. CDH is a source of great distress, with impairment of pleasure and working activities. This decreased of quality of life can result in hopelessness and despair, and suicidal wishes can easily emerge [67]. However, the pain of headaches is itself is a potential independent risk factor for suicide, particularly among those with chronic headache or multiple sources of co-occurring pain [68]. Individuals suffering from chronic pain may be particularly appropriate for suicide screening and intervention efforts. Innamorati and colleagues [69] have proposed a new scale, the Italian Perceived Disability Scale, as screening tool to identify comorbidity with emotional distress and disorders. This scale has proved able to predict suicidal intent in $\mathrm{CDH}$ patients and to assess disability in a sample of patients with $\mathrm{CDH}$ [69].

\section{Treatment}

The use of psychoactive drugs can influence the frequency and modify the clinical features of migraine headaches. For acute treatment, sumatriptan, nonsteroidal anti-inflammatory agents, ergotamine, and dihydroergotamine have been used, and metoclopramide is often co-administered.

The SSRIs (paroxetine and fluvoxamine) remain the firstchoice medications for mood disorders related to migraine, although long-term treatment with serotonergic compounds does not impact the migraine itself. The SSRIs can also be used for the long-term treatment of panic disorder without mood disorders, tension-type headache, obsessive-compulsive disorder and somatoform disorder [70]. Regarding GAD and tension-type headache, the administration of BZDs is possible, but long-term therapy with BZD is not feasible because of the development of tolerance. In GAD long term therapy, SSRI (paroxetine) could represent a valid alternative to BZD if starting with a minimal effective dosage. The aim is to customize treatment as much as possible. The association between migraine and panic disorder and bipolar disorder or unipolar disorder can be treated with VPA, which is effective in the control of panic [71].

For the preventive treatment of mood disorders related to migraine or tension-type headache, the recommended therapy is to use antidepressive tricyclics (TCAs) [72], such as amitriptyline, as monotherapy or a combination of amitriptyline and an SSRI such as paroxetine [16] or flunarizine [73] and mood stabilizers such as lithium [21] or valproate $[73,74]$. These have been tested and found to be
Table 4 Preventive treatments in headache associated with depressive syndrome
Preventive treatment
Migraine + depression + anxious symptoms: antidepressants with sedative properties
TCAs: amitriptyline
SSRIs: paroxetine, fluvoxamine
SNRIs: mirtazepine
Migraine + depression with psychomotor slowing: antidepressants without sedative properties
SSRIs: fluoxetine
Inadvisable drugs
Flunarizine
Beta-blockers

Table 5 Preventive treatments in headache associated with panic disorder

Short-term treatment

BZDs: alprazolam, clonazepam

Long-term treatment

Migraine + panic disorder: VPA

Migraine + panic disorder + bipolar disorder: VPA

Migraine + panic disorder + secondary depression: antidepressants with sedative properties

TCAs: amitriptyline

SSRIs: paroxetine, fluvoxamine

SNRIs: mirtazepine

Migraine + depression + secondary panic disorder

Prevalence of anxiety symptoms: antidepressants with sedative properties

TCAs: amitriptyline

SSRIs: paroxetine, fluvoxamine

SARI: trazodone

Prevalence of psychomotor slowing: antidepressants without sedative properties

SSRIs: fluoxetine

$V P A$ Valproate

useful for migraine prophylaxis. No studies have reported a positive effect of the SSRIs on the aura symptoms. The better strategies are summarized in Tables 4 and 5 .

Although, short-term pharmaceutical care intervention improves patients' mental health, it does not significantly change the number and severity of headaches. However, the increase in self-efficacy and mental health associated with pharmaceutical care may be instrumental in improving the long-term pharmacotherapy of patients with migraine and headache.

\section{Conclusion}

Several studies have analyzed the prevalence and impact of psychiatric disorders among headache patients, and these 
studies have resulted in a better understanding of the relationship between migraine and mood disorders, anxiety, and suicide attempts. Unfortunately, as noted by Silberstein et al. [2], the relationship between headache and psychopathology has often been discussed only clinically rather than systematically studied. Furthermore, the investigation of the interplay of factors that precipitate suicide risk should include the assessment of chronic headache and its effects on well-being. These issues, as well as those discussed in this paper, represent an important area for future research.

Acknowledgments This Tutorial results partly from the teaching of the MP in the Master in Headache Medicine program, Sapienza University of Rome, during the academic year 2008-2009 (http://w3.uniroma1.it/headache). This academic educational activity is performed under the supervision of the WHO Global Campaign to Reduce the Burden of Headache Worldwide "Lifting The Burden"Working Group for Specialist Education (SEWG).

Conflict of interest None.

\section{References}

1. Dodick DW (2006) Chronic daily headache. N Engl J Med 354:158-165. doi:10.1056/NEJMcp042897

2. Silberstein SD, Lipton RB, Sliwinski M (1996) Classification of daily and near-daily headaches: field trial of revised HIS criteria. Neurology 47:871-875

3. Scher AI, Stewart WF, Liberman J, Lipton RB (1998) Prevalence of frequent headache in a population sample. Headache 38:497506. doi:10.1046/j.1526-4610.1998.3807497.x

4. Lu SR, Fuh JL, Chen WT, Juang KD, Wang SJ (2001) Chronic daily headache in Taipei, Taiwan: prevalence, follow-up and outcome predictors. Cephalalgia 21:980-986. doi:10.1046/j.14682982.2001.00294.x

5. Castillo J, Munoz P, Guitera V, Pascual J (1999) Epidemiology of chronic daily headache in the general population. Headache 39:190-196. doi:10.1046/j.1526-4610.1999.3903190.x

6. Headache Classification Committee of the International Headache Society (2004) The international classification of headache disorders, 2nd edition. Cephalalgia 24(Suppl 1):9-160. doi: 10.1111/j.1468-2982.2003.00824.x

7. Silberstein SD, Olesen J, Bousser M, International Headache Society et al (2005) The international classification of headache disorders, 2nd edition (ICHD-II)-revision of criteria for 8.2 Medication-overuse headache. Cephalalgia 25:460-465. doi: 10.1111/j.1468-2982.2005.00878.x

8. Bigal ME, Tepper SJ, Sheftell FD et al (2004) Chronic daily headache: correlation between the 2004 and the 1988 international headache society diagnostic criteria. Headache 44:684691. doi:10.1111/j.1526-4610.2004.04128.x

9. Breslau N, Davis GC (1993) Migraine, physical health and psychiatric disorder: a prospective epidemiologic study in young adults. J Psychiatr Res 27:211-221. doi:10.1016/0022-3956(93) 90009-Q

10. Verri AP, Proietti Cecchini A, Galli C et al (1998) Psychiatric comorbidity in chronic daily headache. Cephalalgia 18(Suppl 21): 45-49

11. Mathew N (1991) Chronic daily headache: clinical features and natural history. In: Nappi G (ed) Headache and depression: serotonin pathways as a common clue. Raven Press, New York, pp 49-58

12. Peres MF, Zukerman E, Young WB, Silberstein SD (2002) Fatigue in chronic migraine patients. Cephalalgia 22:720-724. doi:10.1046/j.1468-2982.2002.00426.x

13. Peres MF, Young WB, Kaup AO et al (2001) Fibromyalgia is common in patients with transformed migraine. Neurology 57:1326-1328

14. Puca F, the Italian Collaborative Group (2000) Psychological and social stressors and psychiatric comorbidity in patients with migraine without aura from headache centers in Italy a comparison with tension-type. J Headache Pain 1:17-32. doi:10.1007/ s101940050005

15. Breslau N, Schultz LR, Stewart WF et al (2000) Headache and major depression: is it the association specific to migraine? Neurology 54:308-313

16. Sheftel FD, Atlas SJ (2002) Migraine and psychiatric comorbidity: from theory and hypotheses to clinical application. Headache 42:934-944. doi:10.1046/j.1526-4610.2002.02217.x

17. Merikangas KR, Merikangas JR, Angst J (1993) Headache syndromes and psychiatric disorders: association and family transmission. J Psychiatr Res 2:197-210. doi:10.1016/0022-3956(93) 90008-P

18. Franchini L, Serretti A, Gasperini M, Smeraldi E (1998) Familial concordance of fluvoxamine response as a tool for differentiating mood disorder pedigrees. J Psychiatr Res 32:255-259. doi: 10.1016/S0022-3956(98)00004-1

19. Mahmood T, Silverstone T (2000) Twin concordance for bipolar disorder and migraines. Am J Psychiatry 157(12):2057. doi: 10.1176/appi.ajp.157.12.2057

20. Oedegaard KJ, Angst J, Neckelmann D, Fasmer OB (2005) Migraine aura without headache compared to migraine with aura in patients with affective disorders. J Headache Pain 6(5):378 386. doi:10.1007/s10194-005-0236-4

21. Franchini L, Bongiorno F, Dotoli D et al (2004) Migraine headache and mood disorders: a descriptive study in an outpatient psychiatric population. J Affect Disord 81(2):157-160. doi: 10.1016/S0165-0327(03)00164-2

22. Breslau N, Davis GC, Andresky P (1991) Migraine, psychiatric disorders, and suicide attempts: an epidemiologic study of young adults. J Psychiatr Res 37:11-23. doi:10.1016/0165-1781(91) 90102-U

23. Post RM, Silberstein SD (1994) Shared mechanisms in affective illness, epilepsy, and migraine. Neurology 44(Suppl 7):S37S47

24. Pandey GN, Dwivedi Y, Rizavi HS et al (2002) Higher expression of serotonin 5-HT2A receptors in the postmortem brains of teenage suicide victims. Am J Psychiatry 159:419-429. doi: 10.1176/appi.ajp.159.3.419

25. Lidberg L, Belfrage H, Bertilsson L et al (2000) Suicide attempts and impulse control disorder are related to low cerebrospinal fluid 5-HIAA in mentally disordered offenders. Acta Psychiatr Scand 101:395-402. doi:10.1034/j.1600-0447.2000.101005395.x

26. Hargreaves RJ, Shepheard SL (1999) Pathophysiology of migraine-new insights. Can J Neurol Sci 26(Suppl 3):S12-S19

27. Shiah IS, Ko HC, Lee JF, Lu RB (1999) Platelet 5-HT and plasma MHPG levels in patients with bipolar I and bipolar II depressions and normal controls. J Affect Disord 52:101-110. doi:10.1016/ S0165-0327(98)00060-3

28. Fasmer OB, Oedegaard KJ (2001) Clinical characteristics of patients with major affective disorders and comorbid migraine. World J Biol Psychiatry 2:149-155

29. Mongini F, Rota E, Deregibus A et al (2006) Accompanying symptoms and psychiatric comorbidity in migraine and tensiontype headache patients. J Psychosom Res 61(4):447-451. doi: 10.1016/j.jpsychores.2006.03.005 
30. Abu-Arefeh I, Russell G (1995) Prevalence of headache and migraine in schoolchildren. Br Med J 309:765-769

31. Sillanpää M (1983) Prevalence of headache in prepuberty. Headache 23:10-14

32. Fasmer OB (2001) The prevalence of migraine in patients with bipolar and unipolar affective disorders. Cephalalgia 21(9):894899. doi:10.1046/j.1468-2982.2001.00279.x

33. Endicott NA (1989) Psychophysiological correlates of "bipolarity". J Affect Disord 17:47-56. doi:10.1016/0165-0327(89) 90023-2

34. Puca F, the Italian Collaborative Group (1999) Psychiatric comorbidity and psychosocial stress in patients with tension-type headache from headache centers in Italy. Cephalalgia 19:159 164. doi:10.1046/j.1468-2982.1999.1903137.x

35. Merikangas KR, Stevens DE, Angst J (1993) Headache and personality: results of a community sample of young adults. J Psychiatr Res 27:187-196. doi:10.1016/0022-3956(93)90007-O

36. Merikangas KR, Stevens DE, Angst J (1994) Psychopathology and headache syndromes in the community. Headache 34:S17S22. doi:10.1111/j.1526-4610.1994.hed3408s17.x

37. Breslau N, Merikangas K, Bowden CL (1994) Comorbidity of migraine and major affective disorders. Neurology 44(10 suppl 7): S17-S22

38. Breslau N, Andresky P (1995) Migraine, personality and psychiatric comorbidity. Headache 35:382-386. doi:10.1111/j.15264610.1995.hed3507382.x

39. Breslau N (1992) Migraine, suicidal ideation, and suicide attempts. Neurology 42:392-395

40. Merikangas KR, Stevens DE (1997) Comorbidity of migraine and psychiatric disorders. Neurol Clin 15:115-123. doi:10.1016/S07338619(05)70298-X

41. Holroyd KA, Stensland M, Lipchik GL et al (2000) Psychosocial correlates and impact of chronic tension-type headaches. Headache 40:3-16. doi:10.1046/j.1526-4610.2000.00001.x

42. Breslau N, Lipton RB, Stewart WF et al (2003) Comorbidity of migraine and depression: Investigating potential etiology and prognosis. Neurology 60:1308-1312

43. Merikangas KR, Angst J, Isler H (1990) Migraine and psychopathology: results of the Zurich cohort study of young adults. Arch Gen Psychiatry 47:849-853

44. Swartz KL, Pratt LA, Armenian HK et al (2000) Mental disorders and the incidence of migraine headaches in a community sample. Arch Gen Psychiatry 57:945-950. doi:10.1001/archpsyc.57. 10.945

45. Zwart JA, Dyb G, Hagen K et al (2003) Depression and anxiety disorders associated with headache frequency. The NordTrondelag Study. Eur Neurol 10:147-152. doi:10.1046/j.14681331.2003.00551.x

46. McWilliams LA, Goodwin RD, Cox BJ (2004) Depression and anxiety associated with three pain conditions: results from a nationally representative sample. Pain 111:77-83. doi:10.1016/j. pain.2004.06.002

47. Patel NV, Bigal ME, Kolodner KB et al (2004) Prevalence and impact of migraine and probable migraine in a health plan. Neurology 63:1432-1438

48. Juang KD, Wang SJ, Fuh JL et al (2000) Comorbidity of depressive and anxiety disorders in chronic daily headache and its subtypes. Headache 40:818-823. doi:10.1046/j.1526-4610.2000. 00148.x

49. Mitsikostas DD, Thomas AM (1999) Comorbidity of headache and depressive disorders. Cephalalgia 19:211-217. doi:10.1046/ j.1468-2982.1999.019004211.x

50. De Benedditis G, Lorenzetti A (1992) Minor stressful life events (daily hassles) in chronic primary headache relationship with MMPI personality patterns. Headache 32:330-332. doi:10.1111/ j.1526-4610.1992.hed3207330.x
51. Fernandez E, Sheffield J (1996) Relative contributions of life events versus daily hassles to the frequency and intensity of headaches. Headache 36:595-602. doi:10.1046/j.1526-4610.1996. 3610595.x

52. Marazziti D, Toni C, Pedri S, Bonuccelli U et al (1995) Headache, panic disorder and depression: comorbidity or a spectrum? Neuropsychobiology 31:125-129. doi:10.1159/000119182

53. Vasconcelos LP, Costa Silva M, Coelho Costa EA, da Silva AA Jr, Santiago Gomez R, Teixeira AL (2008) Obsessive compulsive disorder and migraine: case report, diagnosis and therapeutic approach. J Headache Pain 9:397-400

54. Mathew NT, Reuveni U, Perez F (1987) Transformed or evolutive migraine. Headache 27:102-106. doi:10.1111/j.1526-4610. 1987.hed2702102.x

55. Mongini F, Defilippi N, Negro C (1997) Chronic daily headache. A clinical and psychological profile before and after treatment. Headache 37:83-87. doi:10.1046/j.1526-4610.1997.3702083.x

56. Galli F, Canzano L, Scalisi G, Guidetti V (2009) Psychiatric disorders and headache familial recurrence: a study on 200 children and their parents. J Headache Pain 10:187-197. doi: 10.1007/s10194-009-0105-7

57. Mazzone L, Vitiello B, Incorpora G, Mazzone D (2005) Behavioural and temperamental characteristics of children and adolescents suffering from primary headache. Cephalgia 26:194-201. doi:10.1111/j.1468-2982.2005.01015.x

58. Garcia-Coll C, Kagan J, Reznik JS (1984) Behavioural inhibition in young children. Child Dev 55:1005-1019. doi:10.2307/ 1130152

59. Kagan J, Reznick JS, Clarke C et al (1984) Behavioural inhibition to the unfamiliar. Child Dev 55:2212-2225. doi:10.2307/ 1129793

60. Goodyer IM, Ashby L, Altham PME et al (1993) Temperament and major depression in 11-16 year olds. J Child Psychol Psychiatry 34:1409-1423. doi:10.1111/j.1469-7610.1993.tb02099.x

61. Kelvin RG, Goodyer IM, Altham PME (1996) Temperament and psychopathology amongst siblings of probands with depressive and anxiety disorders. J Child Psychol Psychiatry 37:543-550. doi:10.1111/j.1469-7610.1996.tb01440.x

62. Anttilla P, Sourander A, Metsähonkala L, Aromaa M, Helenius H, Silanpää M (2004) Psychiatric symptoms in children with primary headache. J Am Acad Adolesc Psychiatry 43:412-419. doi:10.1097/00004583-200404000-00007

63. Saper JR, Lake AE III (2002) Borderline personality disorder and the chronic headache patient: review and management recommendations. Headache 42:663-674. doi:10.1046/j.1526-4610. 2002.02156.x

64. Hegarty A (1993) The prevalence of migraine in borderline personality disorder. Headache 33:271

65. Stewart WF, Linet MS, Celentano DD (1989) Migraine headaches and panic attacks. Psychosom Med 51:559-569

66. Wang SJ, Juang KD, Fuh JL, Lu SR (2007) Psychiatric comorbidity and suicide risk in adolescents with chronic daily headache. Neurology 68(18):1468-1473. doi:10.1212/01.wnl.0000260 607.90634.d6

67. De Filippis S, Erbuto D, Gentili F et al (2008) Mental turmoil, suicide risk, illness perception, and temperament, and their impact on quality of life in chronic daily headache. J Headache Pain 9:349-357. doi:10.1007/s10194-008-0072-4

68. Ilgen MA, Zivin K, McCammon RJ, Valenstein M (2008) Pain and suicidal thoughts, plans and attempts in the United States. Gen Hosp Psychiatry 30(6):521-527. doi:10.1016/j.genhosppsych. 2008.09.003

69. Innamorati M, Pompili M, De Filippis S et al (2009) The validation of the Italian Perceived Disability Scale (IPDS) in chronic daily headache sufferers. J Headache Pain 10:21-26. doi:10.1007/ s10194-008-0076-0 
70. Savarese M, Guazzelli M, Prudenzano MP et al (2005) Tertiary treatment for psychiatric comorbidity in headache patients. J Headache Pain 6(4):231-233. doi:10.1007/s10194-005-0193-y

71. Malcangio M, Bowery NG (1996) GABA and its receptors in the spinal cord. Trends Pharmacol Sci 17:457-462. doi:10.1016/ S0165-6147(96)01013-9

72. Singh NN, Misra S (2002) Sertraline in chronic tension-type headache. J Assoc Physicians India 50:871-872

73. Mitsikostas DD, Polychronidis I (1997) Valproate versus flunarizine in migraine prophylaxis: a randomized, double-open, clinical trial. Fund Neurol 12:267-276
74. Nieper HA (1973) Clinical applications of lithium orotate: a two year study. J Acad Prevent Med 2:18-22

75. Atasoy HT, Atasoy N, Unal AE, Emre U, Sumer M (2005) Psychiatric comorbidity in medication overuse headache patients with pre-existing headache type of episodic tension-type headache. Eur J Pain 9(3):285-291

76. Wang SJ, Fuh JL, Lu SR, Liu CY, Hsu LC, Wang PN, Liu HC (2000) Chronic daily headache in Chinese elderly: prevalence, risk factors, and biannual follow-up. Neurology 54:314-319 